\title{
Detailed structure of the upper mantle discontinuities around the Japan subduction zone imaged by receiver function analyses
}

\author{
Takashi Tonegawa $^{1}$, Kazuro Hirahara ${ }^{1}$, and Takuo Shibutani ${ }^{2}$ \\ ${ }^{1}$ Graduate School of Environmental Studies, Nagoya University, Nagoya 464-8602, Japan \\ ${ }^{2}$ Disaster Prevention Research Institute, Kyoto University, Uji 611-0011, Japan
}

(Received February 9, 2004; Revised November 10, 2004; Accepted November 11, 2004)

\begin{abstract}
High-resolution receiver function (RF) images of the upper mantle structure beneath the Japan Islands are obtained by RF analysis of the P-wave coda portions of 389 teleseismic events observed at 138 high-density broadband stations. We construct RFs through frequency-domain division using a water level of 0.01 and Gaussian low-pass filters of 1.0, 0.5, 0.3, and $0.1 \mathrm{~Hz}$, and produce depth-migrated RFs using the one-dimensional IASP91 velocity model. The RF images clearly resolve the subducting Pacific Plate to a depth of $200 \mathrm{~km}$, and reveal a local $30 \mathrm{~km}$ elevation of the $410 \mathrm{~km}$ discontinuity within the subducting plate. The $660 \mathrm{~km}$ discontinuity is also found to exhibit a broad $50 \mathrm{~km}$ depression under the influence of the stagnating slab. From analysis of the frequency dependence of the RFs, the thickness of the $410 \mathrm{~km}$ discontinuity is inferred to vary on a relatively local scale, whereas the $660 \mathrm{~km}$ transition is sharp throughout the Japan Islands.
\end{abstract}

Key words: Receiver function, upper mantle discontinuity, Japan subduction zone.

\section{Introduction}

It is widely accepted that seismic velocity discontinuities exist globally at depths of approximately 410 and $660 \mathrm{~km}$ in the upper mantle. These discontinuities exhibit global and local undulations due to both thermal anomalies in the mantle and the Clapeyron slope associated with mineral phase change. The $410 \mathrm{~km}$ discontinuity is commonly interpreted as representing the phase change of $\alpha$-olivine to $\beta$-modified spinel, with a positive Clapeyron slope (Katsura and Ito, 1989), while the $660 \mathrm{~km}$ boundary is considered to be related to the phase change of the $\gamma$-spinel to perovskite + magnesiowustite (e.g., Ringwood, 1991) with a negative Clapeyron slope (Ito and Takahashi, 1989; Bina and Helffrich, 1994). Therefore, cold thermal anomalies such as descending slabs are inferred to shift the $410 \mathrm{~km}$ discontinuity upward and the $660 \mathrm{~km}$ boundary downward, whereas hot thermal anomalies such as upwelling mantle plumes have the opposite effect.

Previous seismic reflection and refraction studies have revealed the global variations in the depth and thickness of the upper mantle discontinuities. Revenaugh and Jordan (1989, 1991) determined that the depths of the 410 and $660 \mathrm{~km}$ discontinuities vary by up to $20 \mathrm{~km}$, while Shearer (1991) and Shearer and Masters (1992) found that the variations may be up to $30-40 \mathrm{~km}$. Recent studies have revealed more details about the depth variations of the upper mantle discontinuities (e.g., Flanagan and Shearer, 1998; Gu and Dziewonski, 1998; Gu et al., 2003). In local-scale surveys focusing on the Japan subduction zone, Castle and Creager (1997) suggested that the $660 \mathrm{~km}$ discontinuity is depressed by about

Copy right(c) The Society of Geomagnetism and Earth, Planetary and Space Sciences (SGEPSS); The Seismological Society of Japan; The Volcanological Society of Japan; The Geodetic Society of Japan; The Japanese Society for Planetary Sciences; TERRAPUB.
$80 \mathrm{~km}$ due to stagnation of the Pacific Plate (PAC), with actual depths of 650-730 km. Collier and Helffrich (1997), on the other hand, determined that the maximum depth of the $660 \mathrm{~km}$ discontinuity is $700 \mathrm{~km}$, and Li et al. (2000) predicted a maximum depth of $680 \mathrm{~km}$ in the $30-34^{\circ} \mathrm{N}$ region, except for a narrow region between $136^{\circ} \mathrm{E}$ and $139^{\circ} \mathrm{E}$ where the discontinuity occurred at $730 \mathrm{~km}$. Previous works have also suggested an upward shift of the $410 \mathrm{~km}$ discontinuity near subduction zones. Vidale and Benz (1992) reported an ascent of ca. $15 \mathrm{~km}$, and Collier and Helffrich (1997) determined that the discontinuity reached a minimum depth of only $350 \mathrm{~km}$ in the Izu-Bonin region, with depths of about $380 \mathrm{~km}$ in the region south of Japan $\left(31^{\circ} \mathrm{N}, 136-138^{\circ} \mathrm{E}\right)$. In determining the detailed structure of the rapidly descending slab and the surrounding mantle, it is also important to consider the existence of metastability below $410 \mathrm{~km}$ (e.g. Sung and Burns, 1976) and stagnation of the subducting slab in the region around $660 \mathrm{~km}$ (e.g. Fukao et al., 2001).

In this study, we applied the receiver function (RF) analyses developed by Langston $(1977,1979)$ to reveal the detailed structure of these upper mantle phase boundaries in the Japan subduction zone. In the Japan Islands, several short-period and broadband seismic networks have recently been deployed or are under construction, representing one of the highest density deployments of seismic stations in the world. The large number of waveforms recorded by this high-density broadband network makes it possible to achieve a dramatic improvement in resolution for the RF images compared with previous RF studies such as Li et al. (2000).

As in previous RF studies, assuming all phases of RFs are due to P-to-S wave (Ps) conversion at depth, we performed depth-migration of the RFs using the one-dimensional (1D) IASP91 velocity model (Kennett and Engdahl, 1991), af- 


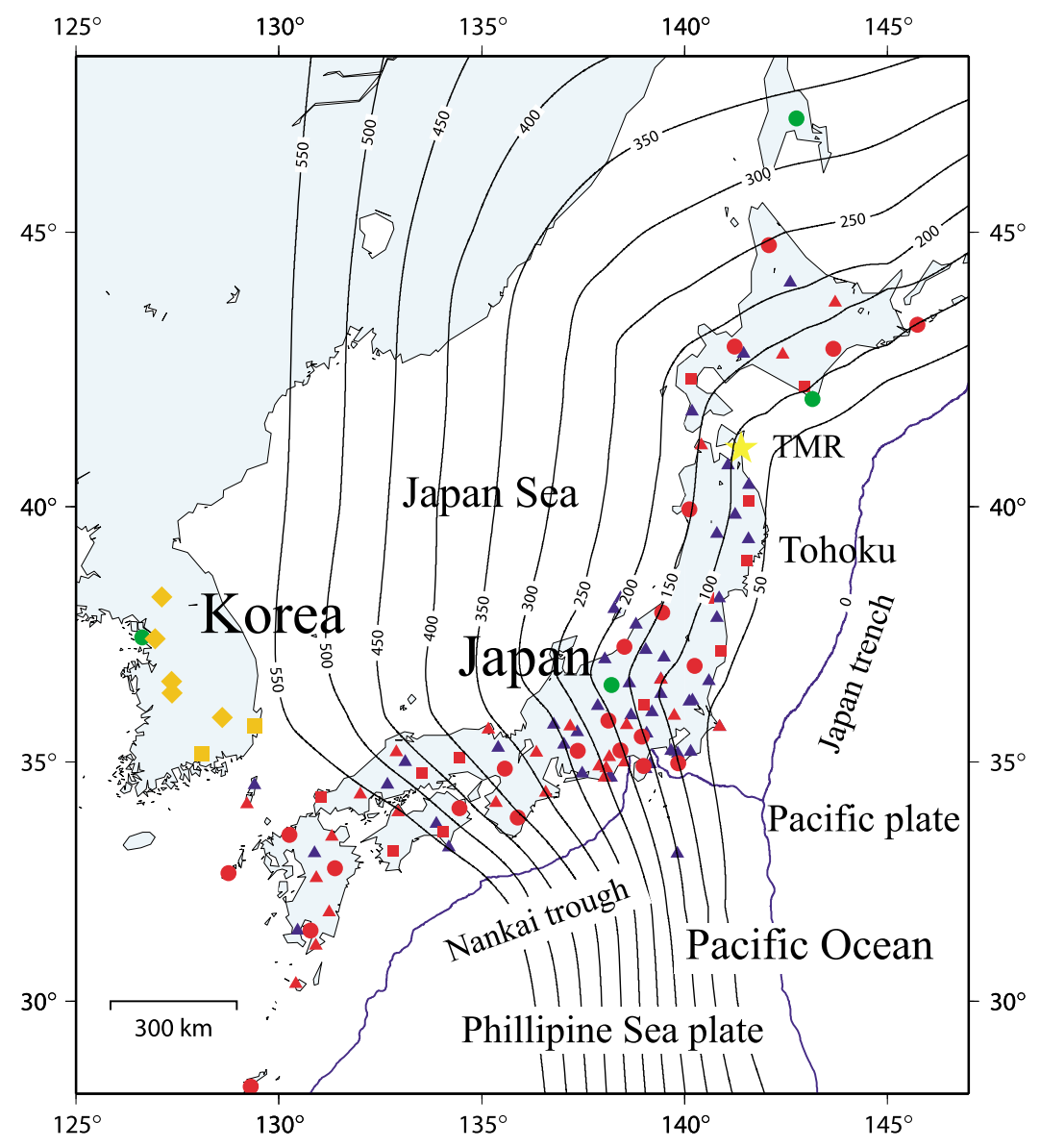

Fig. 1. Location of the stations. Stations used in this study consist of 64 F-net, 63 J-array, 4 IRIS, 7 Korean broadband stations. Red color indicates F-net stations except for TMR, and blue, green and orange ones do J-array, IRIS, Korean stations, respectively. Triangle, circle, square and diamond indicate seismometers of STS-2, STS-1, CMG-1T, CMG-3TB, respectively. Yellow colored star represents the location of the station TMR. Also the black curves denote the contour depths corresponding to the top surface of the PAC obtained from the distribution of deep and intermediate-deep earthquakes from Zhao et al. (1994).

fording stacked RF images on two-dimensional (2D) vertical profiles. These vertical profiles were then used to investigate the spatial variations in the depth of the upper mantle discontinuities in relation to the descending PAC. We also examined the frequency dependence of RF amplitudes in order to identify spatial variations in the transition widths of the discontinuities, and evaluated the effect of lateral variations in seismic velocity on the resultant migrated RFs. As recent tomographic studies have pointed out (e.g. Fukao et al., 2001), the Japan subduction zone hosts large lateral variations in seismic velocity due to the descent of the cold PAC slab to comparatively deep mantle. Hence, we also obtained depth-migrated RFs using a recent tomographic three-dimensional (3D) velocity model, and compared the results with those for the $1 \mathrm{D}$ velocity models.

\section{Data}

Although the seismic networks in the Japan Islands consist of both short-period and broadband stations, we only employed records from broadband stations in this study. RF analyses were applied to the later phases of the direct $\mathrm{P}$ wave observed at $63 \mathrm{~J}$-array, $64 \mathrm{~F}$-net, and 4 Incorporated Research Institutions for Seismology (IRIS) broadband stations. J-array is operated by Japanese universities and the Japan Meteorological Agency (JMA), and F-net is main- tained by the National Research Institute for Earth Science and Disaster Prevention (NIED). We also included the data recorded at 7 broadband stations in Korea, which were provided by the Korean Institute of Geosciences and Mineral Resources (KIGAM). The data set thus consisted of records from 138 broadband stations, the locations of which are shown in Fig. 1.

We constructed the RFs using waveforms for 389 teleseismic events with magnitudes greater than 5.5 occurring between 1998 and 2003. The epicentral distribution is shown in Fig. 2. The epicentral distances of these teleseismic earthquakes are between $30^{\circ}$ and $98^{\circ}$, with back azimuths (BAZs) in almost all directions. The data set consisted of 30,000 waveforms, of which 7,725 waveforms with good signal to noise ratios were selected for analysis after careful examination. The high-quality data and high density of stations are expected to provide a far more detailed upper mantle structure for the Japan Islands compared to previous RF analyses.

\section{Methods}

\subsection{Construction of RFs}

Following Langston (1977, 1979), we obtained radial RFs by deconvolving radial components from vertical ones through conventional spectral division using a water level 


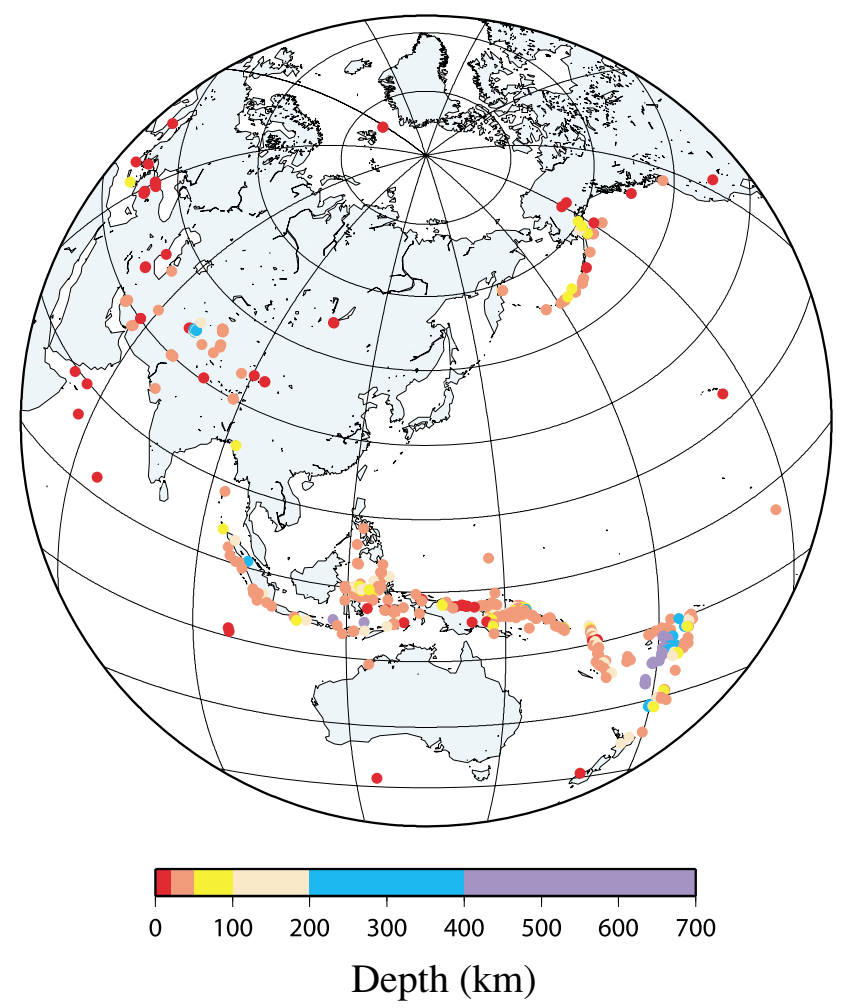

Fig. 2. Equi-distant azimuthal distribution of the 389 teleseismic events analyzed in this study $\left(1998 \sim 2003, M>5.5, \Delta>30^{\circ}\right)$. The hypocentral depths are indicated by different colors.
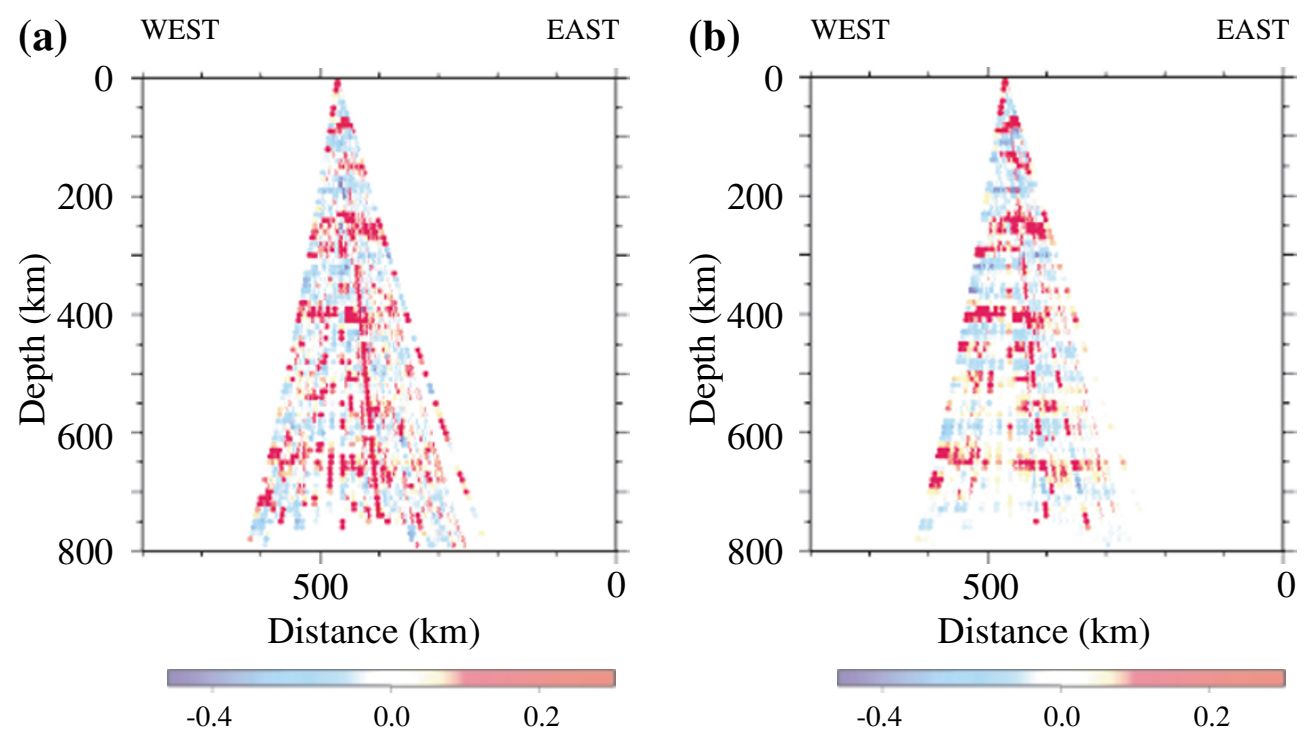

Fig. 3. Comparison of original RFs with SVD filtered ones observed at a station, TMR (see Fig. 1). (a) Depth-transformed RFs projected onto an east-west cross-section and (b) corresponding SVD filtered one with $n=6$.

method. The water level parameter was set at 0.01 , which is a percentage with respect to the maximum spectral amplitude. A Gaussian filter was applied for low-pass filtering at $0.3 \mathrm{~Hz}$. For inspection of the frequency dependence of the RFs, we prepared three other sets of RFs using low-pass filters at $1.0,0.17$ and $0.1 \mathrm{~Hz}$ with the same water level.

\subsection{Depth migration}

To image the underground structure, the RFs need to be converted from time-domain RFs to depth-domain ones. Assuming that all later phases in the radial RFs are due to Ps phases converted at discontinuities beneath stations, depthmigrated RFs were generated using the 1D IASP91 velocity model as a reference (Kennett and Engdahl, 1991), as used in previous studies. We also prepared sets of RFs constructed using the 1D JMA velocity model and the 3D tomographic velocity model for the Japan Islands (Nakamura et al., 2000) in order to discuss the effect of the reference velocity model in this analysis. In the construction of the $3 \mathrm{D}$ migrated RFs, ray-bending due to the $3 \mathrm{D}$ velocity structure has a second-order effect on the travel time, particu- 


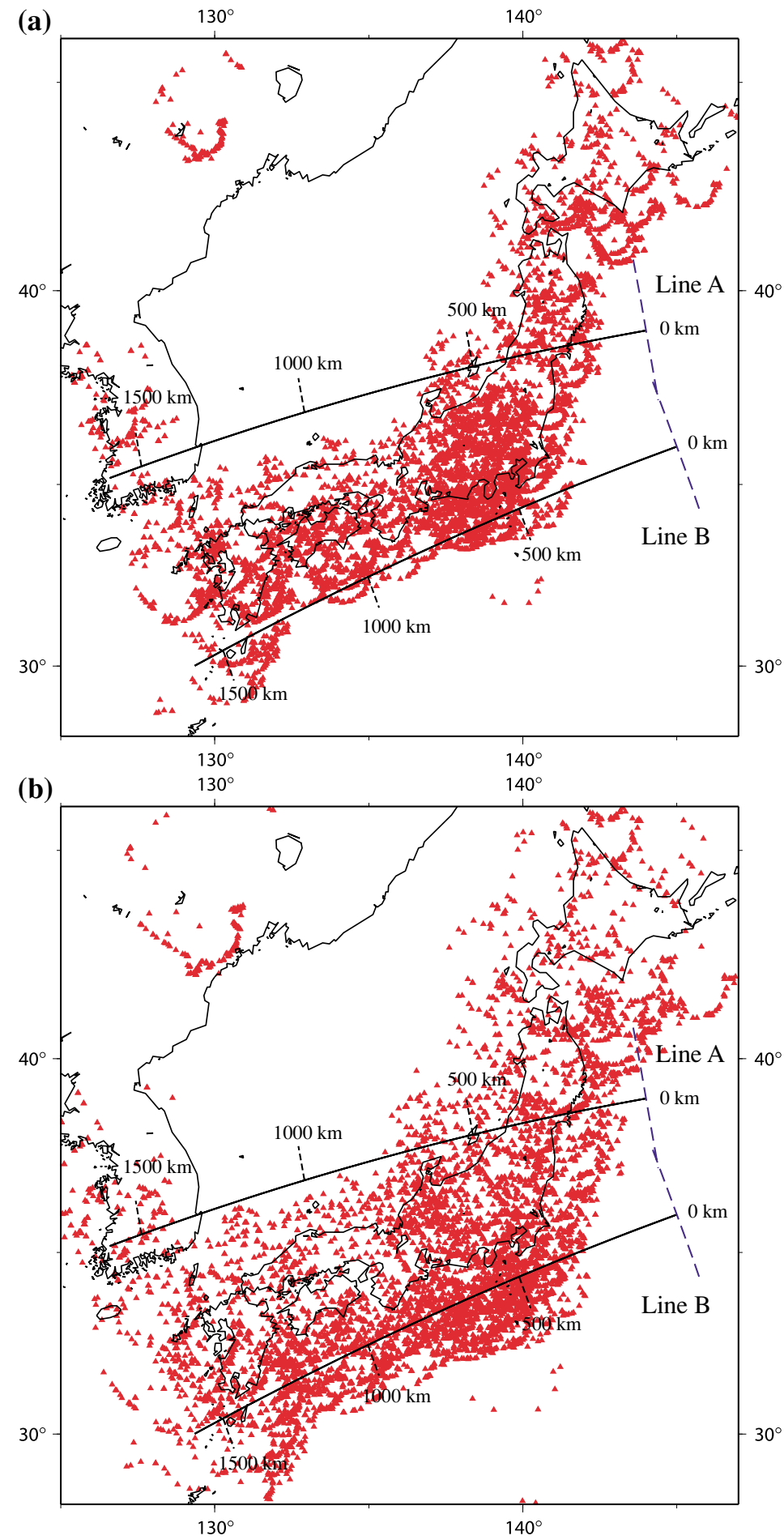

Fig. 4. Piercing points of Ps converted phases and the locations of the cross-sections, Lines A and B. (a) Distribution of piercing points at a depth of $410 \mathrm{~km}$ indicated by red triangles. Lines show the locations of two cross-sections determined by consideration of the piercing point density. (b) Same as in Fig. 4(a), but at $660 \mathrm{~km}$. In these figures, the black broken lines show the scale of the cross-section, and the blue broken line show the width of the cross-section.

larly for teleseismic rays. In addition, computations of raybending due to the $3 \mathrm{D}$ vecocity structure are time consuming. Therefore, in the construction, we simply employed the ray-path of the Ps converted phase computed based on the average $1 \mathrm{D}$ velocity model derived form the $3 \mathrm{D}$ model, and corrected the travel time using $3 \mathrm{D}$ velocity perturbation values.

\subsection{Singular value decomposition filtering}

The radial RFs plots with respect to BAZ revealed several coherent Ps phases generated at discontinuities. Singular value decomposition (SVD) filtering enhances these coherent phases and suppresses the incoherent phases with largest appropriate eigenimages. See Chevrot and Girardin (2000) for details of the SVD filtering technique.

The traveltime difference between a direct $\mathrm{P}$ wave and a 

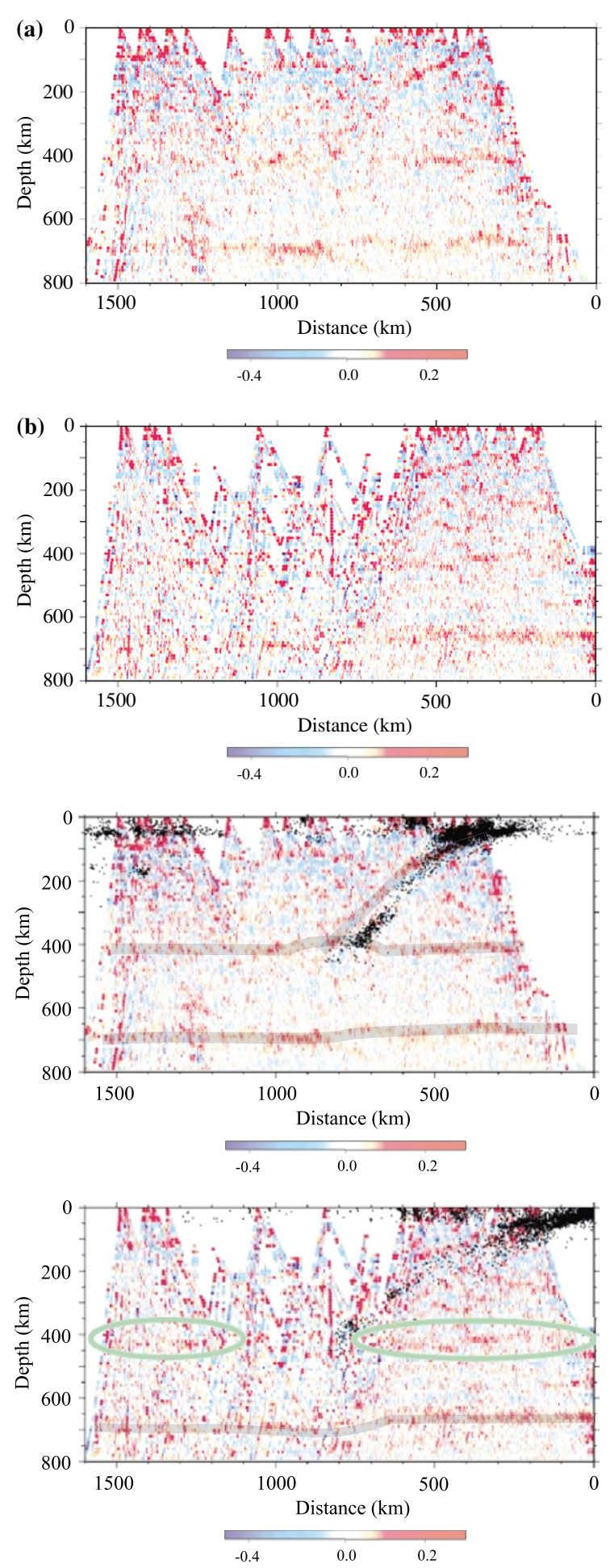

Fig. 5. RF images along Lines A and B. (a), RF image at depths from 0 to $800 \mathrm{~km}$ along Line B for $0.3 \mathrm{~Hz}$ low-pass filtered RFs transformed by referring to the IASP91 velocity model. Red and blue represent positive and negative RF amplitudes, respectively. (b) Same as in Fig. 5(a), but along Line A. (c) Same as in Fig. 5(a), but with earthquake hypocenters and our interpretations on discontinuities. (d) Same as in Fig. 5(b), but with earthquake hypocenters and our interpretations on discontinuities.

Ps converted wave is a function of the incident angle, and is often referred to as distance moveout. For the phases converted at shallow depths, the distance moveout is so small that it can be ignored. However, in the case of the deep upper mantle discontinuities, the influence of distance
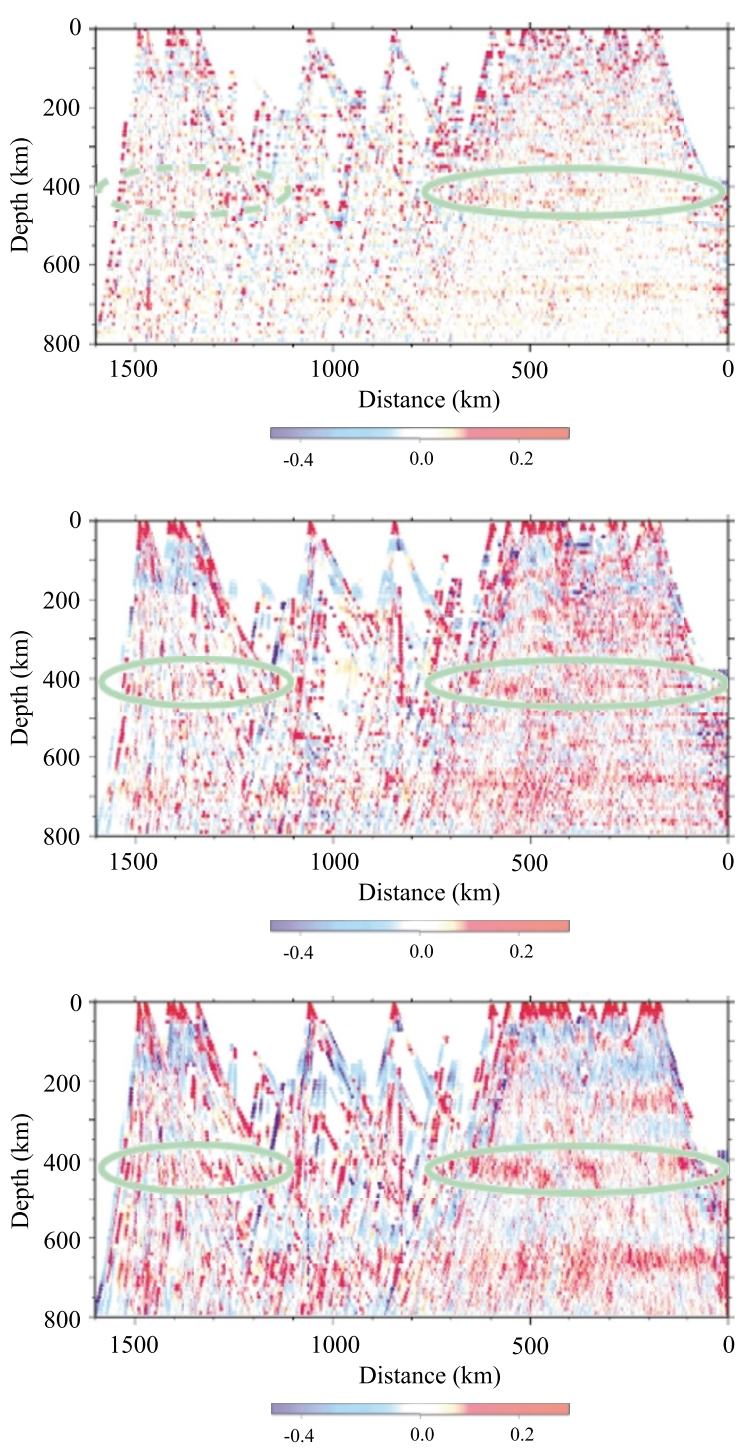

Fig. 6. Frequency-dependent RF images at depths from 0 to $800 \mathrm{~km}$ along Line A for (a) $1.0 \mathrm{~Hz}$, (b) $0.17 \mathrm{~Hz}$ and (c) $0.1 \mathrm{~Hz}$ low-pass filtered $\mathrm{RFs}$, respectively. Note that the $410 \mathrm{~km}$ discontinuity appears in the RF image with lower frequency, which portions are indicated by the green circles, while disappears in the one with higher frequency, which portion is indicated by the broken green circle (Fig. 6(a)).

moveout is large. Therefore it is not appropriate to apply SVD filtering to the time-domain RFs, which include information from the deep upper mantle. To correct large distance moveouts, the SVD filter is applied after transformation of the time-domain RFs into depth-domain ones. This approach allows the coherent phases to be extracted effectively. SVD filtering was performed here using the 6 largest eigenimages. As shown in Fig. 3, where the RFs are projected on an EW trending vertical plane for station TMR, the SVD filtering with $n=6$ provides a better RF image.

\subsection{Additional processing}

To obtain clearer RF images, we further processed the RFs as follows. The Ps converted points were calculated based on the BAZ, the distance from the station, and the converted depth, and a 3D RF image was then obtained by stacking and plotting the amplitudes in cells of $(1 \mathrm{~km} \times$ $1 \mathrm{~km} \times 10 \mathrm{~km})$. However, the $3 \mathrm{D}$ image at this stage 
remains somewhat fragmentary due to the finite number of events and broadband stations, although the dataset used here is much larger than in previous ones. Therefore, by selecting profiles in which a large number of rays cross, we projected the $3 \mathrm{D}$ image onto a series of $2 \mathrm{D}$ profiles showing the average values in cells on projected planes within a certain width. In this study, a width of $\pm 200 \mathrm{~km}$ from the line of the cross-section was applied to capture the relatively deep discontinuities. The cross-sections for plotting the RFs were chosen based on the density of Ps converted points. The locations of two cross-sections and the Ps converted points for the 410 and $660 \mathrm{~km}$ discontinuities are shown in Figs. 4(a) and (b), and Figs. 5(a) and (b) exhibit the resultant $\mathrm{RF}$ images for these cross-sections. In these cross-sections, red represents positive RF polarity, indicating a velocity jump from fast to slow in the upward direction (e.g., the top surface of the subducting slab, and the 410 and the 660 $\mathrm{km}$ discontinuities), and blue denotes a negative polarity, indicating a velocity jump from slow to fast in the upward direction (e.g., the lower boundary of the subducting slab). In the plots, the RF amplitudes are normalized to those of the direct $\mathrm{P}$ waves.

We also produced topographic maps to aid discussion of the variations in discontinuity depth. After identifying the maximum positive amplitudes in each RF in the depth ranges of 380-440 km and $640-700 \mathrm{~km}$, the average differences from the depths of 410 and $660 \mathrm{~km}$ were estimated in $0.5^{\circ} \times 0.5^{\circ}$ cells. The grid data was then smoothed using the surface command in GMT (Wessel and Smith, 1998).

\section{Results}

Figures 5(a) and (b) show the $0.3 \mathrm{~Hz}$ low-pass-filtered RFs along Lines A and B, and Figs. 5(c) and (d) include also the corresponding event distributions for the period 19641995 estimated by the International Seismological Centre (ISC). The interpreted PAC and 410 and $660 \mathrm{~km}$ discontinuities are indicated by black lines in the figure, corresponding to positive RF amplitudes.

As shown in Figs. 5(a) and (c), positive RF amplitudes corresponding to the westward-dipping PAC can be traced clearly down to a depth of about $200 \mathrm{~km}$, and less clearly to a depth of $400 \mathrm{~km}$, in good agreement with the event distribution. Although Yamauchi et al. (2003) showed that the northwestward-dipping Philippine Sea Plate (PHS) extends to a depth of $60 \mathrm{~km}$ or more in southwest Japan, it could not be resolved clearly in the present images due to the use of a relatively long-period component. These figures also show the large RF amplitudes of the 410 and $660 \mathrm{~km}$ discontinuities beneath the Japan Islands. The average depth of the $410 \mathrm{~km}$ discontinuity is estimated to be about 410 $\mathrm{km}$, without large undulations.

As shown in Fig. 5(a), however, the positive RF amplitudes associated with the locally elevated $410 \mathrm{~km}$ discontinuity seem to deviate from those for the dipping PAC. The upward shift of the $410 \mathrm{~km}$ discontinuity is estimated to be $30 \mathrm{~km}$ within the region of slab where the PAC penetrates the discontinuity, with an actual depth of $380-410 \mathrm{~km}$. This result is in good agreement with the results of previous work (e.g. Collier and Helffrich, 1997).

The positive RF amplitudes corresponding to the $660 \mathrm{~km}$ discontinuity exhibit a gradual westward depression, but the undulation cannot be determined further west of Japan along Line B. However, along line A in Fig. 5(b), which includes the Korean data, the $660 \mathrm{~km}$ discontinuity can be seen to gradually descend westwards from $650 \mathrm{~km}$ to 700 $\mathrm{km}$, and then gradually ascend further west from $700 \mathrm{~km}$ to $680 \mathrm{~km}$. In other words, the $660 \mathrm{~km}$ discontinuity exhibits a broad depression of ca. $50 \mathrm{~km}$ through a depth variation from $650 \mathrm{~km}$ to $700 \mathrm{~km}$ using the IASP91 model.

Figures 6(a)-(c) show the reconstruction along Line A using the 3.0, 0.17, and $0.1 \mathrm{~Hz}$ low-pass-filtered RFs. In Fig. 6(a), the positive RF amplitudes corresponding to the $410 \mathrm{~km}$ discontinuity beneath the Korean Peninsula seem to disappear, whereas those beneath the Japan Islands can be clearly recognized. Conversely, in Figs. 5(d), 6(b) and 6(c), the $410 \mathrm{~km}$ discontinuity can also be recognized beneath the Korean Peninsula.

\section{Discussion}

\subsection{Relationship between the subducting slab and the upper mantle discontinuities}

The results above indicate a local elevation of the $410 \mathrm{~km}$ discontinuity within the slab. This can be attributed to both the thermal anomaly of the slab and the positive Clapeyron slope of the $410 \mathrm{~km}$ discontinuity. In other words, since the Clapeyron slope of the $410 \mathrm{~km}$ discontinuity is positive, related to $\alpha$-olivine to $\beta$-modified spinel phase transformation, the cold thermal anomaly of the subducting slab causes upward distortion of the phase boundary within the slab. It is also well known that a region of metastability may exist inside the cold slab where the temperature remains sufficiently low to delay the phase transformation. If the subducting slab includes such a metastable zone below the $410 \mathrm{~km}$ discontinuity, the $\alpha$-olivine to $\beta$-modified spinel phase boundary will be locally and significantly depressed within the slab. However, despite the high resolution of the present analysis, such fine structures remain difficult to resolve. Koper et al. (1998) indicated that metastability may not be able to be detected by seismic analysis unless a highly detailed local analysis is performed, such as that of Iidaka and Suetsugu (1992). Nevertheless, the present results indicate a local elevation of $30 \mathrm{~km}$ for the $410 \mathrm{~km}$ discontinuity due to the cold penetrating slab.

Figures 5(b) and (d) show the gradual depression of the $660 \mathrm{~km}$ discontinuity, induced by the negative Clapeyron slope of the $\gamma$-spinel to perovskite + magnesiowustite phase transition. However, the downward displacement of the $660 \mathrm{~km}$ discontinuity is expected to be more abrupt than suggested by the figures, as the cold material of the PAC descends rapidly through the $660 \mathrm{~km}$ zone. The gradual distortion seen in the present results is considered to be due to the effect of stagnation of the PAC. If the cold material of the stagnated slab does not exted beneath Korea, the discontinuity should return to a depth of $650 \mathrm{~km}$ there. However, the results in Fig. 5(d) indicates a depth of $680 \mathrm{~km}$ beneath Korea, suggesting that the stagnated PAC affects the $660 \mathrm{~km}$ discontinuity even beneath Korea. Previous tomography surveys have indicated that the subducted PAC does not penetrate simply into the lower mantle, but instead stagnates at the $660 \mathrm{~km}$ discontinuity in the region of the 


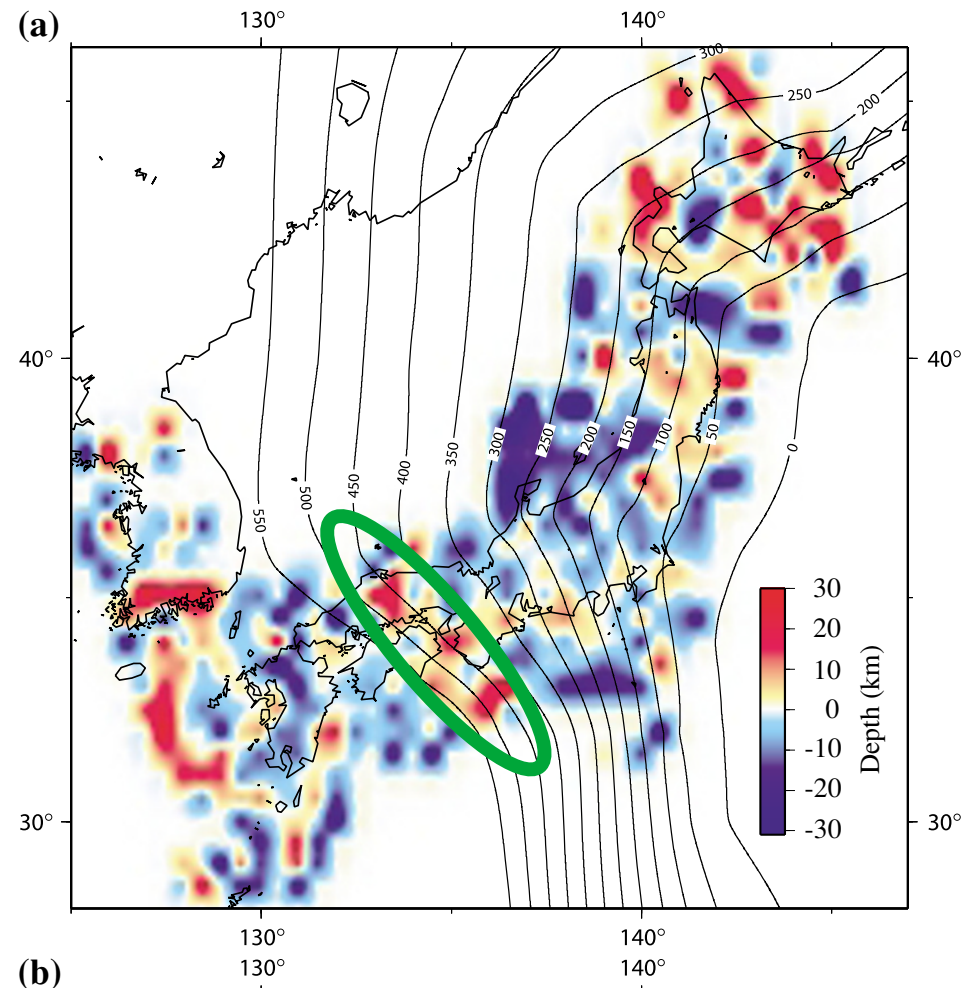

(b)

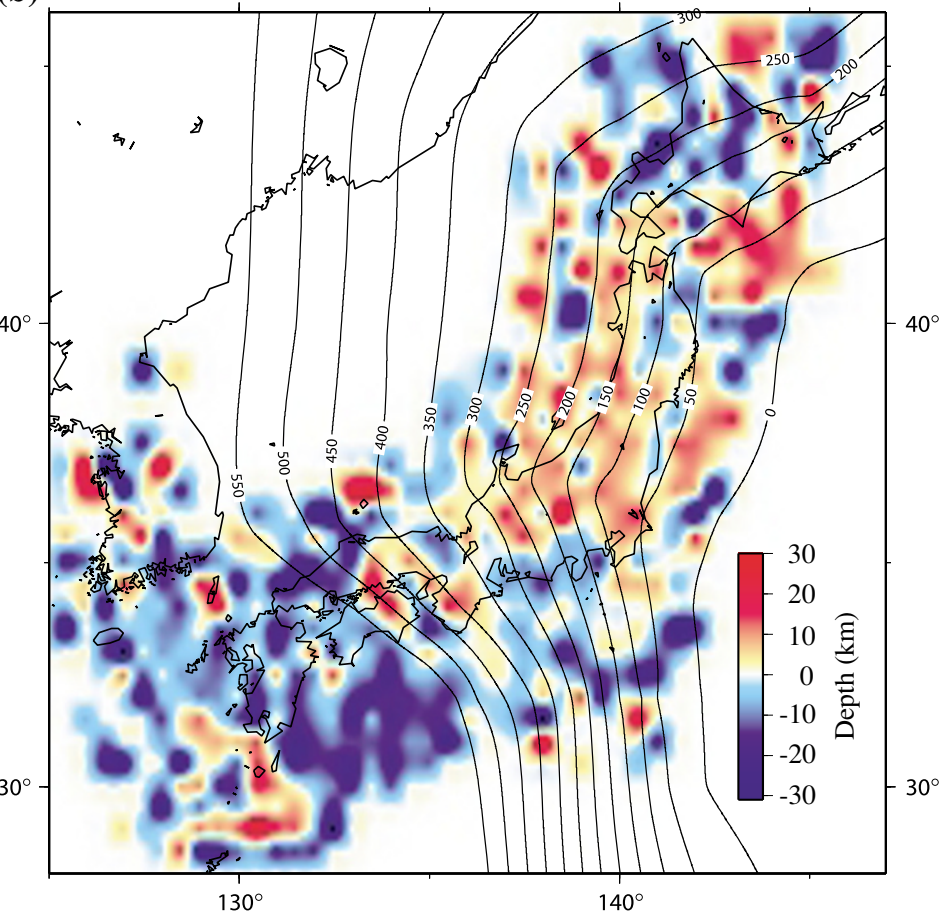

Fig. 7. Topographical contour maps of the undulations of the 410 and $660 \mathrm{~km}$ discontinuities. (a) Depth variations of the $410 \mathrm{~km}$ discontinuity for 0.3 Hz low-pass filtered RFs. Colors indicate the depth differences from $410 \mathrm{~km}$. Red to yellow color shows the amount of the elevation from $410 \mathrm{~km}$, and pale-blue to blue shows the one of depression from $410 \mathrm{~km}$. The green broken circle indicates the uplift portion of the $410 \mathrm{~km}$ discontinuity. (b) Same as in Fig. 7(a), but the depth variations of the $660 \mathrm{~km}$ discontinuity. Red to yellow color shows the amount of the elevation from $670 \mathrm{~km}$, and pale-blue to blue shows the one of depression from $670 \mathrm{~km}$.

Japan subduction zone (Fukao et al., 2001). Hence, the 660 $\mathrm{km}$ discontinuity beneath the Japan Islands is gradually and broadly depressed by up to $50 \mathrm{~km}$ under the influence of the relatively large cold body of the slab.

Figures 7(a) and (b) represent topographical contour maps showing the deviation of the 410 and $660 \mathrm{~km}$ discontinuities from the $0.3 \mathrm{~Hz}$ low-pass-filtered RFs. As can be seen in Fig. 7(a), a local upward displacement of the 410 $\mathrm{km}$ discontinuity is inferred near a PAC contour depth of $400 \mathrm{~km}$ (red area in green circle), while Fig. 7(b) reveals regional contrast between the northeast (dominantly red) and the southwest (dominantly blue) of Japan, implying a westward dip of the $660 \mathrm{~km}$ discontinuity due to stagnation of the PAC. Thus, in addition to the cross-sections discussed 
in previous sections, the undulations of the discontinuities can also be seen in the topographical contour maps of depth variation.

\subsection{Frequency dependence of RFs and thickness of the discontinuities}

For a fixed frequency, the RF amplitudes are sensitive to both the thickness and the velocity difference of the discontinuity. The frequency dependence, however, is mainly controlled by the thickness of the discontinuity. The RF amplitudes will be high if the analyzed wavelength is longer than the width of the discontinuity. Consequently, it is necessary to consider the frequency dependence of the RF amplitudes with respect to the thickness of the discontinuity.

In the present results, positive RF amplitudes corresponding to the $410 \mathrm{~km}$ discontinuity can be recognized beneath the Korean Peninsula in Figs. 5(d), 6(b) and 6(c), but not in Fig. 6(a) (green circles in each figure). These frequency dependences of RF amplitudes suggest there exists a difference in the thickness of the $410 \mathrm{~km}$ discontinuity beneath Korea and Japan (Tohoku region).

Many investigators have discussed the sharpness of these discontinuities. For example, Vidale et al. (1995) indicated that the thickness of the $410 \mathrm{~km}$ discontinuity varies from 2 to $35 \mathrm{~km}$. The major factors controlling the thickness of the phase boundary are temperature, water content, and hydrogen diffusion. Specifically, the zone in which $\alpha$-olivine and $\beta$-modified spinel coexist has been reported to become wider as the temperature decreases (Bina and Helffrich, 1994), and the discontinuity has been suggested to spread by as much as $40 \mathrm{~km}$ under hydrous conditions but to become sharper under the effect of hydrogen diffusion (Smyth and Frost, 2002). The effect of temperature is considered to be much weaker than that of water content, as shown by Helffrich and Wood (1996), who found that a temperature reduction of $800 \mathrm{~K}$ thickens the discontinuity by only 10 $\mathrm{km}$. Thus, the effect of temperature can be ignored in the present analysis because no large temperature differences occur at a depth of ca. $400 \mathrm{~km}$ beneath Japan and Korea, as predicted in previous numerical simulations (e.g., Yoshioka and Sanshadokoro, 2002). The effect of hydrogen remains controversial, and is dependent on the distribution of water content above and below the $410 \mathrm{~km}$ discontinuity. As the water distribution around the $410 \mathrm{~km}$ discontinuity is unclear and currently under debate (e.g., Bercovici and Karato, 2003), the present analysis is confined to discussion only of the effect of lateral variations in water content around the $410 \mathrm{~km}$ discontinuity.

The $410 \mathrm{~km}$ discontinuity exhibits some local variation in thickness in the present results, with a general trend for a thicker transition zone beneath the Korean Peninsula and a sharper transition beneath the Japan Islands (Tohoku region). A possible reason for this difference may be the higher water content beneath Korea than beneath Japan. In this case, the discontinuity should also be shallower beneath Korea (Smyth and Frost, 2002). However, similar depths are obtained in this study for both Japan and Korea (Fig. 6(c)). This inconsistency should be addressed in future through the incorporation of additional seismological data and more accurate experimental data.

Quantitative estimates of the thickness variations were not made in this study. For quantitative estimates, we need to investigate also the influence of the velocity gradient (e.g. linear or non-linear) within the discontinuity on the frequency-dependence of the depth estimation, as in the case of reflection (Shearer, 2000). Further careful frequency-dependence analyses including modeling of representative waveforms is therefore considered to be necessary in order to quantitatively discuss the detailed variations in thickness and depth.

For the $660 \mathrm{~km}$ discontinuity, however, positive RF amplitudes can be seen clearly in Fig. 6(c) for the longer-period component, and less clearly in Figs. 6(a) and (b) for the shorter-period components. This type of frequency dependence suggests that the transition at $660 \mathrm{~km}$ is relatively sharp. Yamazaki and Hirahara (1994) also reported that the $660 \mathrm{~km}$ discontinuity is $5 \mathrm{~km}$ thick at most, which is consistent with the sharpness of the transition from $\gamma$-spinel to perovskite + magnesiowustite (Ito and Takahashi, 1989). In contrast to the $410 \mathrm{~km}$ discontinuity, this phase boundary would become thinner with increasing water content at that depth. Thus, from the frequency dependence of the characteristics of the $660 \mathrm{~km}$ discontinuity, the $\gamma$-spinel to perovskite + magnesiowustite phase change is considered to occur within a narrow interval of pressure.

\subsection{Multiple phases}

As shown in Fig. 5(a), positive RF amplitudes occur frequently at depths of $100-150 \mathrm{~km}$. These anomalies are considered to represent multiple phases, PpPs or PpSs reflected at the Moho, rather than Ps phases. In particular, the amplitudes of surface-reflected PpPs phases in the RFs are sometimes as large as those of the Ps converted phases, and can be recognized throughout the Japan Islands. However, in the Tohoku region, northeast Japan, it is likely that the Ps phases converted at the upper boundary of the PAC overlap with the multiple phases at depths of about 100-150 km (Fig. 5(b)). Therefore the westward-dipping positive $\mathrm{RF}$ amplitudes deviate from the event distribution along the PAC, as shown in Fig. 5(d). Applying the moveout corresponding to these multiple converted phases may give the same depth transformation of RFs as for Ps phases. Therefore, an appropriate method for stacking these transformed RFs for Ps, PpPs and PpSs phases is necessary to resolve the discontinuities more truly. However, at present, no effective method of removing these multiple phases is available.

\subsection{Influence of reference velocity model}

The RF images obtained in this study using the 1D IASP91 velocity reference model reveal clear undulations of the velocity discontinuities in the upper mantle. However, since the PAC is subducting westwards from the Japan trench to a depth of $600 \mathrm{~km}$ or more, and the PHS is subducting from the Nankai trough to a depth of $60-80 \mathrm{~km}$ in southwest Japan, there exist large lateral variations in seismic velocity beneath the Japan Islands (Fig. 1). It might be suspected that such lateral variations in velocity may induce an apparent undulation in the results if a $1 \mathrm{D}$ velocity model is used. If this were the case, however, the depth of the 410 $\mathrm{km}$ discontinuity should differ between eastern and western Japan because the discontinuity in eastern Japan occurs beneath the high-velocity slab. As no such depth differences can be recognized in the present RF images, where the 410 
km discontinuity exhibits only small undulations except for local elevation within the PAC (Figs. 5(a) and (c)), the lateral variation in velocity is not considered to affect the RF images in this study.

Nevertheless, the possible introduction of apparent undulations was specifically investigated by comparing the results with RFs migrated using a recent tomographic 3D velocity model. Several velocity models derived from traveltime tomography analyses have been published for the Japan Islands. Among them, the 3D Vp and Vs model produced by Nakamura et al. (2000) was used for the present analysis, in which both $\mathrm{Vp}$ and Vs models are defined for the region $20-48^{\circ} \mathrm{N}$ and $120-154^{\circ} \mathrm{E}$ to a depth of $700 \mathrm{~km}$. In this model, the maximum and minimum perturbations in velocity are $8 \%$ and $-8 \%$, respectively. Images of RFs migrated using a 1D JMA velocity model similar to the average 1D velocity model of Nakamura's 3D model (Nakamura et al., 2000) were also compared.

Figures 8(a) and (b) show the cross-sections along Line B by the 1D JMA and 3D Nakamura velocity models. Comparison of these figures with Fig. 5(a) indicates that the absolute depths of the 410 and $660 \mathrm{~km}$ discontinuities determined by the 1D IASP91 velocity model are shallower than for the other reference models. The RF images for the 1D JMA and 3D Nakamura models indicate depths of 410-430 $\mathrm{km}$ and $680-730 \mathrm{~km}$ for the two discontinuities, slightly deeper than the depths of 400-420 km and 650-700 km for the 1D IASP91 model. It is considered that such differences can be attributed to the inclusion of lower-velocity regions in the two alternative velocity models, particularly in the region shallower than $400 \mathrm{~km}$. The RF images of the dipping PAC and the 410 and $660 \mathrm{~km}$ discontinuities are clearer in Fig. 8(b) than in Fig. 5(a), except for the western region where the $3 \mathrm{D}$ model has poor resolution.

Besides the minor difference in the absolute depths of the discontinuities, all of the models afford very similar results in clear undulatins of the velocity discontinuities. Thus, the lateral variations in velocity beneath the Japan subduction zone appear to have very little effect specific to the 1D IASP91 model, and it is considered unnecessary to re-interpret the main results. However, to obtain a more precise RF image for the west of Japan and discuss the effect of the stagnant slab on the $660 \mathrm{~km}$ discontinuity in more detail, it will be necessary to use a new regional 3D velocity model with higher resolution in the stagnating slab region.

\section{Conclusion}

Through receiver function analyses, we successfully resolved the structure of the descending PAC to a depth of $200 \mathrm{~km}$ or more, and identified undulations of the 410 and $660 \mathrm{~km}$ seismic velocity discontinuities beneath the Japan Islands. Two-dimensional cross-sections were produced for central and southwest Japan, where stations capable of detecting Ps converted waves at depths of 410 and $660 \mathrm{~km}$ are deployed in a high-density network, revealing the detailed structure of the seismic velocity discontinuities. The 410 $\mathrm{km}$ discontinuity was found to exhibit a local elevation of $30 \mathrm{~km}$ within the cold subducting PAC, while the $660 \mathrm{~km}$ discontinuity was revealed to undergo a gradual depression
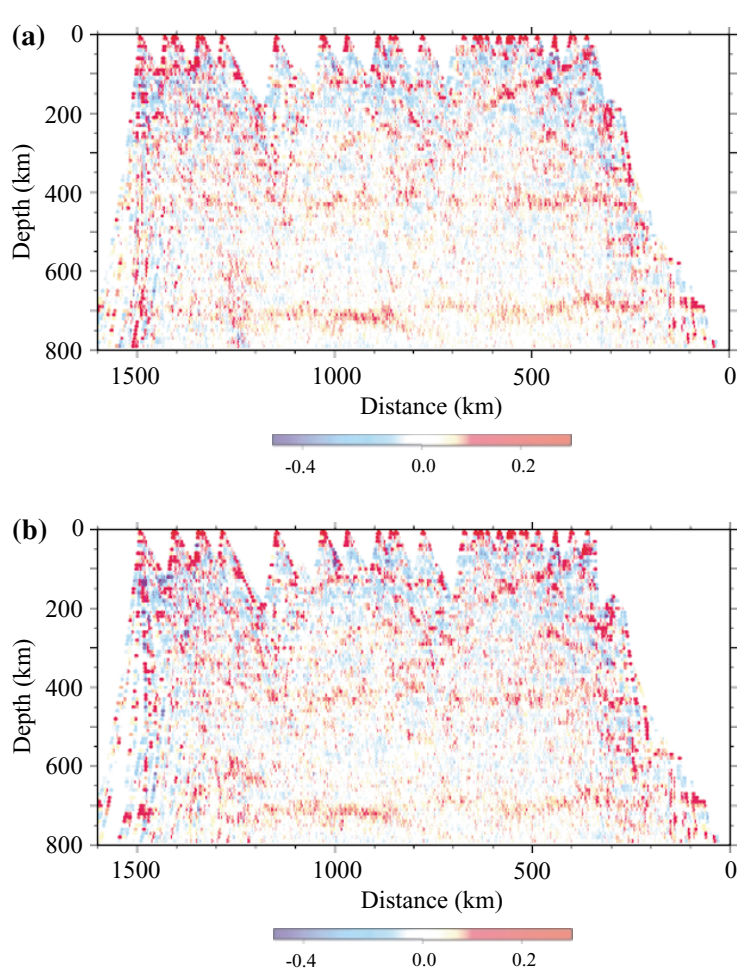

Fig. 8. RF images along Line B migrated using 1-D JMA and 3-D velocity reference velocity models (a) RF image at depths from 0 to $800 \mathrm{~km}$ along Line B for $0.3 \mathrm{~Hz}$ low-pass filtered RFs migrated by referring to the 1-D JMA velocity model. (b) Same as in Fig. 8(a), but referring to 3-D velocity model by Nakamura et al. (2000).

of $50 \mathrm{~km}$ under the influence of the stagnating PAC as a large cold thermal anomaly. These features could also be recognized in the topographical contour maps of the discontinuities. The frequency dependence of the RFs indicates that the thickness of the $410 \mathrm{~km}$ discontinuity varies on a relatively local scale, with a broader zone of $\alpha$-olivine to $\beta$-modified spinel phase transition beneath the Korean Peninsula than beneath the Japan Islands. In contrast, the $\gamma$ spinel to perovskite + magnesiowustite phase transition produces the $660 \mathrm{~km}$ discontinuity is relatively sharp throughout the Japan Islands. This study demonstrates the effectiveness of receiver function imaging for reproducing in detail the seismic velocity discontinuity within and around subducting slabs.

Acknowledgments. We thank K. Obara and K. Shiomi in NIED for providing F-net data, people in universities and JMA for providing J-array data, and J. Jeon and Y. Park in KIGAM for providing broadband data. We are also grateful to M. Nakamura in JMA for providing 3-D velocity data. We used a software package, GMT (Wessel and Smith, 1998), to draw maps. This study is funded by Grand-in-Aid for Scientific Research (B) (1434013) of MEXT. Constructive comments by two reviewers (H. Gilbert and an anonymous reviewer) and editor E. Fukuyama greatly improved the manuscript.

\section{References}

Bercovici, D. and S. Karato, Whole mantle convection and the transitionzone water filter, Nature, 39-44, 2003.

Bina, C. R. and G. R. Helffrich, Phase transition Clapeyron slopes and transition zone seismic discontinuity topography, J. Geophys. Res., 99, 15853-15860, 1994 
Castle, J. C. and K. C. Creager, Seismic evidence against a mantle chemical discontinuity near $660 \mathrm{~km}$ depth beneath Izu-Bonin, Geophys. Res. Lett., 24, 241-244, 1997.

Chevrot, S. and N. Girardin, On the detection and identification of converted and reflected phases from receiver functions, Geophys. J. Int., 141, 801-808, 2000.

Collier, J. D. and G. R. Helffrich, Topography of the " 410 " and " 660 " km seismic discontinuities in the Izu-Bonin subduction zone, Geophys. Res. Lett., 24, 1535-1538, 1997.

Flanagan, M. P. and P. M. Shearer, Global mapping of topography on transition zone discontinuities by stacking SS precursors, J. Geophys. Res., 103, 2673-2692, 1998.

Fukao, Y., S. Widiyantoro, and M. Obayashi, Stagnant slabs in the upper and lower transition region, Rev. Geophys., 39, 291-323, 2001.

Gu, Y. and A. M. Dziewonski, Global de-correlation of the topography of transition zone discontinuities, Earth Planet. Sci. Lett., 157, 57-67, 1998.

Gu, Y., A. M. Dziewonski, and G. Ekstrom, Simultaneous inversion for mantle shear velocity and topography of transition zone discontinuities, Geophys. J. Int., 154, 559-583, 2003.

Helffrich, G. R. and B. J. Wood, $410 \mathrm{~km}$ discontinuity sharpness and the form of the olivine $\alpha-\beta$ phase diagram: Resolution of apparent seismic contradictions, Geophys. J. Int., 126, F7-F12, 1996.

Iidaka, T. and D. Suetsugu, Seismological evidence for metastable olivine inside a subducting slab, Nature, 356, 593-595, 1992.

Ito, E. and E. Takahashi, Post spinel transformations in the system $\mathrm{Mg}_{2} \mathrm{SiO}_{4}-\mathrm{Fe}_{2} \mathrm{SiO}_{4}$ and some geophysical implications, J. Geophys. Res., 94, 10637-10646, 1989.

Katsura, T. and E. Ito, The system $\mathrm{Mg}_{2} \mathrm{SiO}_{4}-\mathrm{Fe}_{2} \mathrm{SiO}_{4}$ at high pressures and temperatures: Pricise determination of stabilities of olivine, modified spinel and spinel, J. Geophys. Res., 94, 15663-15670, 1989.

Kennett, B. L. N. and E. R. Engdahl., Travel times for global earthquake location and phase identification, Geophys. J. Int., 105, 429-465, 1991.

Koper, K. D., D. A. Wiens, L. M. Dorman, J. A. Hildebrand, and S. C. Webb, Modeling the Tonga slab: Can travel time data resolve a metastable olivine wedge?, J. Geophys. Res., 103, 30079-30100, 1998.

Langston, C. A., The effect of planar dipping structure on source and receiver responses for constant ray parameter, Bull. Seismol. Soc. Am., 67, 1029-1050, 1977.

Langston, C. A., Structure under Mount Rainier, Washington, inferred from teleseismic body waves, J. Geophys. Res., 84, 4749-4762, 1979.

Li, X., S. V. Sobolev, R. Kind, X. Yuan, and Ch. Estabrook, A detailed receiver function image of the upper mantle discontinuities in the Japan subduction zone, Earth Planet. Sci. Lett., 183, 527-541, 2000.

Nakamura, M., Y. Yoshida, H. Kuroki, K. Yoshizawa, D. Zhao, H. Takayama, T. Yamazaki, K. Fujiwara, N. Hamada, J. Kasahara, T. Kanazawa, S. Kodaira, T. Sato, H. Shiniobara, and R. Hino, Threedimensional $\mathrm{P}$ and $\mathrm{S}$ wave velocity structure beneath Japan, Programme Abstaracts, Seis. Soc. Japan, 2000 Fall meeting, P050, 2000 (in Japanese)

Revenaugh, J. and T. H. Jordan, A study of mantle layering beneath the western Pacific, J. Geophys. Res., 94, 5787-5813, 1989.

Revenaugh, J. and T. H. Jordan, Mantle layering from ScS Reverberations 2. The transition zone, J. Geophys. Res., 96, 19763-19780, 1991.

Ringwood, A. E., Phase transformations and their bearing on the constitution and dynamics of the mantle, Geochim. Cosmochim. Acta, 55, 20832110, 1991

Shearer, P. M., Constraints on upper mantle discontinuities from observations of long-period reflected and converted phases, J. Geophys. Res., 96, 18,147-18,182, 1991.

Shearer, P. M., Upper mantle seismic discontinuities, in Earth's Deep Interior: Mineral Physics and Tomography from the Atomic to the Global Scale, edited by S. Kararo, A. M. Forte, R. C. Liebermann, G. Masters, and L. Stixrude, pp. 115-131, AGU, 2000.

Shearer, P. M. and T. G. Masters, Global mapping of topography on the $660 \mathrm{~km}$ discontinuity, Nature, 355, 791-796, 1992.

Smyth, J. R. and D. J. Frost, The effect of water on the 410 km discontinuity: An experimental study, Geophys. Res. Let., 29, 10.1029/2001GL014418, 2002.

Sung, C. M. and R. G. Burns, Kinetics of high-pressure phase transformations: Implications to the evolution of the olivine-spinel transition in the downgoing lithosphere and its consequences on the dynamics of the mantle, Tectnophysics., 31, 1-32, 1976.

Vidale, J. E. and H. M. Benz, Upper-mantle seismic discontinuities and the thermal structure of subduction zones, Nature, 356, 678-682, 1992.

Vidale, J. E., X. Y. Ding, and S. P. Grand, The 410-km depth discontinuity: A sharpness estimate from near critical reflection, Geophys. Res. Lett., 22, 2557-2560, 1995.

Wessel, P. and W. H. F. Smith, New, improved version of Generic Mapping Tools released, EOS Trans. Amer. Geophys. U., 79(47), pp. 579, 1998.

Yamauchi, M., K. Hirahara, and T. Shibutani, High-resolution receiver function imaging of the seismic velocity discontinuities in the crust and the uppermost mantle beneath southwest Japan, Earth Planets Space, 55, 59-64, 2003.

Yamazaki, A. and K. Hirahara, The thickness of upper mantle discontinuities, as inferred from short period J-Array data, Geophys. Res. Lett., 21 , 1811-1814, 1994.

Yoshioka, S. and H. Sanshadokoro, Numerical simulations of deformation and dynamics of horizontally lying slab, Geophys. J. Int., 151, 69-82, 2002.

Zhao, D., A. Hasegawa, and H. Kanamori, Deep structure of Japan subduction zone as derived from local, regional and teleseismic events, $J$. Geophys. Res., 99, 22313-22329, 1994.

T. Tonegawa (e-mail: tonegawa@eps.nagoya-u.ac.jp), K. Hirahara, and T. Shibutani 